\title{
Selenium uptake onto natural pyrite
}

\author{
Enzo Curti $\cdot$ Laure Aimoz $\cdot$ Akira Kitamura
}

Received: 3 July 2012 / Published online: 25 July 2012

(C) Akadémiai Kiadó, Budapest, Hungary 2012

\begin{abstract}
Se}$ is a major dose-determining redox-sensitive nuclide in safety analysis of radioactive waste disposal sites. In aqueous solutions, selenium forms soluble anionic species $\left(\mathrm{Se}^{\mathrm{IV}} \mathrm{O}_{3}{ }^{2-}\right.$ and $\left.\mathrm{Se}^{\mathrm{VI}} \mathrm{O}_{4}{ }^{2-}\right)$ that hardly sorb on negatively charged surfaces of common host-rock minerals. However, Se is known to have a strong affinity with sulphides and interacts with pyrite, a common minor mineral of argillaceous rocks being considered as host formations for radioactive waste repositories. In this study, we present micro- and bulk X-ray spectroscopy data ( $\mu$-XRF, $\mu$-XANES, and EXAFS) showing that, under nearly anoxic conditions, dissolved $\mathrm{SeO}_{3}{ }^{2-}$ and $\mathrm{SeO}_{4}{ }^{2-}$ sorb directly onto the pyrite surface and are subsequently reduced to $\mathrm{Se}^{0}$ with increasing ageing time (up to 8 months). These results suggest that the mobility of ${ }^{79} \mathrm{Se}^{\mathrm{IV}}$ released from radioactive waste could greatly decrease through uptake on the pyrite surface followed by transformation into a sparingly soluble reduced form.
\end{abstract}

Keywords X-ray spectroscopy $\cdot$ Redox $\cdot$ Selenium · Pyrite $\cdot$ Radioactive waste $\cdot$ Micro-XANES $\cdot$ Micro-XRF . Sorption

E. Curti $(\bowtie) \cdot$ L. Aimoz $\cdot$ A. Kitamura

Laboratory for Waste Management, Paul Scherrer Institut, 5232 Villigen PSI, Switzerland

e-mail: enzo.curti@psi.ch

Present Address:

A. Kitamura

Geological Isolation Research and Development Directorate, Japan Atomic Energy Agency, Tokai, Naka, Ibaraki 319-1194, Japan

\section{Introduction}

Radioactive waste produced worldwide by the operation of nuclear power plants is nowadays a high-priority global environmental problem. The generally accepted option for the safe disposal of radioactive waste is the long-term storage in a system of protective materials (engineered barriers) within a suitable deep geological formation [1]. This multiple barrier system must guarantee the long-term isolation of the waste from the biosphere.

In most scenarios for planned repository sites (see e.g. $[2,3])$ ground water will slowly penetrate the repository and aqueous corrosion will ultimately release the longlived radionuclides from the waste. The mobility of each radionuclide will then largely depend on its chemical properties, specifically on its capability to bind to minerals and materials in the near-field and far-field of the repository.

In safety assessment calculations, long-lived nuclides such as ${ }^{14} \mathrm{C},{ }^{129} \mathrm{I},{ }^{36} \mathrm{Cl}$ and ${ }^{79} \mathrm{Se}$ dominate the calculated dose curves in safety assessment calculations of repository sites [2]. These nuclides form anionic species that do not sorb significantly on exposed surfaces of major minerals present in the repository near-field (e.g. clays, carbonates, and sulfates), since their surfaces are negatively charged under the neutral to alkaline pHs prevailing in such environments. They are therefore considered to be mobile compared with fission products and actinides dissolved as cationic species.

However, the case of ${ }^{79} \mathrm{Se}$ (half-life $3.77 \times 10^{5}$ years) is somehow peculiar, because selenium may be stable in geochemical environments either as reduced species $\left(\mathrm{Se}^{-\mathrm{II},-\mathrm{I}, 0}\right)$ or as oxidized species $\left(\mathrm{Se}^{\mathrm{IV}, \mathrm{VI}}\right)$. Whereas reduced Se species are fairly insoluble and immobile, oxidized species form soluble, poorly sorbing $\mathrm{Se}^{\mathrm{IV}} \mathrm{O}_{3}{ }^{2-}$ 
(selenite) and $\mathrm{Se}^{\mathrm{VI}} \mathrm{O}_{4}{ }^{2-}$ (selenate) oxo-anions. In vitrified high-level waste derived from reprocessing of spent nuclear fuel, Se resides in the oxidized $\mathrm{Se}^{\mathrm{IV}}$ form (see later) and will therefore be released to the aqueous solution as easily soluble selenite anions. For this reason, ${ }^{79} \mathrm{Se}$ is normally treated as soluble anionic nuclide in safety assessments. However, in such calculations the effects of minor minerals are conservatively neglected. For instance, there is increasing evidence that Se may bind, through reductive sorption processes, to minor sulfide minerals such as pyrite $\left(\mathrm{FeS}_{2}\right)$ and pyrrhotite $(\mathrm{FeS})$.

In the high-level waste repository planned in Switzerland, pyrite will be present as a minor mineral both in bentonite, foreseen as buffer material to seal the underground tunnels hosting the waste (about $0.3 \mathrm{wt} \%$ ), and in the surrounding Opalinus clay host formation (about 1 wt\%) [2]. Pyrite has a negative surface charge above $\mathrm{pH}_{\mathrm{pzc}}$ of 1.7 [4], and is therefore not expected to bind anions via electrostatic forces (outer sphere complexes). Nevertheless, significant uptake of selenium on pyrite from selenite/selenate solutions was observed in batch uptake experiments [5]. This quantitative uptake study suggested reduction of dissolved $\mathrm{Se}^{\mathrm{IV}}$ by sulfides and other Fe(II)-bearing minerals, which was confirmed by subsequent EXAFS/XANES studies [6-8].

In this work, $\mathrm{Se}^{\mathrm{IV}}$ and $\mathrm{Se}^{\mathrm{VI}}$ uptake on natural pyrite was studied at $80{ }^{\circ} \mathrm{C}$ under nearly anoxic conditions by micro $\mathrm{X}$-Ray fluorescence ( $\mu$-XRF), micro X-ray absorption near edge spectroscopy ( $\mu$-XANES) and bulk extended X-ray absorption fine structure (EXAFS) spectroscopy, after interaction with $\mathrm{Na}_{2} \mathrm{SeO}_{3}$ and $\mathrm{Na}_{2} \mathrm{SeO}_{4}$ solutions during up to 8 months. The aims of this investigation were: (a) to study the distribution of Se on the pyrite surface at the microscopic (micrometer) scale and the kinetics of related redox processes, with special attention to possible differences between the uptake from $\mathrm{Se}^{\mathrm{IV}}$ and $\mathrm{Se}^{\mathrm{VI}}$ bearing solutions; (b) to determine the atomic-scale coordination environment of Se sorbed on the pyrite and (c), to understand the mechanisms through which Se is bound to pyrite. By combining the information obtained, consequences in view of the future treatment of ${ }^{79} \mathrm{Se}$ in safety assessment calculations are evaluated.

\section{Materials and methods}

Mineral and solutions preparation

The use of natural pyrite was preferred due to the complexity of laboratory procedures for synthesizing pure pyrite $\left(\alpha-\mathrm{FeS}_{2}\right)$ free of other $\mathrm{Fe}_{\mathrm{x}} \mathrm{S}_{\mathrm{y}}$ sulfides [9, 10]. Pyrite samples from the Huanzala (Peru) and Navajun (Spain) mines purchased from Ward's Natural Science, Rochester,
$\mathrm{NY}$, were used. Huanzala is a $\mathrm{Zn}-\mathrm{Pb}$ strata-bound hydrothermal ore deposit hosted in a Cretaceous limestone formation, with pyrite formation occurring at early stages of mineralization as fine-grained to coarse-grained granular masses. The Navajun ore, hosted in a Jurassic marl formation, is characterized by euhedral $\mathrm{cm}$ to $\mathrm{dm}$ sized wellshaped cubic pyrite crystals. The X-ray diffraction patterns of the sample powders, recorded on a Phillips Xpert-Pro diffractometer $\left(\mathrm{CuK} \alpha\right.$ radiation, $2 \theta$ from $5^{\circ}$ to $\left.70^{\circ}\right)$ confirmed pyrite as the only detectable crystalline phase.

For the $\mu$-XAS/ $\mu$-XRF measurements, Navajun pyrite crystals were cut into $7 \times 7 \times 2 \mathrm{~mm}^{3}$ chips $(\sim 0.5 \mathrm{~g})$ and polished under normal air. All subsequent steps were carried out in a $\mathrm{N}_{2}$-flushed glove box ( 5 ppm $\mathrm{O}_{2} \max$ ). The chips were re-polished with diamond paste to eliminate any surface oxidation artifact and then introduced in glass bottles filled with $50 \mathrm{ml}$ of $0.01 \mathrm{M} \mathrm{Na}_{2} \mathrm{SeO}_{3}$ or $0.01 \mathrm{M}$ $\mathrm{Na}_{2} \mathrm{SeO}_{4}$ solution, with or without $0.001 \mathrm{M} \mathrm{NaHS}$. Addition of NaHS was intended to provide completely anoxic conditions. All solutions were prepared in the glove box using analytical grade reagents (Fluka or Sigma-Aldrich) and Milli-Q ${ }^{\circledR}$ water (Millipore, Billerica, USA).

Huanzala pyrite for the bulk Se-K EXAFS experiments was also prepared in the glove box. After grinding in an agate mortar and sieving, the two finer fractions $(63-250 \mu \mathrm{m}$ and $<63 \mu \mathrm{m}$ ) were washed with concentrated (38\%) $\mathrm{HCl}$ during at least $6 \mathrm{~h}$ in order to digest iron oxide traces.

Approximately $0.4 \mathrm{~g} \quad(<63 \mu \mathrm{m}$ fraction $)$ or $0.8 \mathrm{~g}$ (63-250 $\mu \mathrm{m}$ fraction) of the pyrite powder were introduced into glass bottles and filled with 50 or $100 \mathrm{ml}$, respectively, of Se-solution (0.01 $\mathrm{M} \mathrm{Na}_{2} \mathrm{SeO}_{3}$ or $0.01 \mathrm{M} \mathrm{Na}_{2} \mathrm{SeO}_{4}$ ).

All samples were equilibrated at $80{ }^{\circ} \mathrm{C}$ in an oven inside the glove box. The pyrite powder suspensions were shaken by hand at least once per week and periodically adjusted to $\mathrm{pH} \sim 8.0$ by addition of $\mathrm{HCl}$ or $\mathrm{NaOH}$. Except for one sample where substantial $\mathrm{pH}$ drops were observed (Se-23, see later) the $\mathrm{pH}$ remained fairly stable and only minimal adjustments were needed. After a reaction time of 2 weeks (sample Se-07) or 2 months (all other samples), $2.5 \mathrm{ml}$ of solution were pipetted and passed through a filter with molecular weight cut-off (MWCO) of $5 \times 10^{4}$ Dalton. The first $0.5 \mathrm{ml}$ aliquot of filtrate served to equilibrate the filter with $\mathrm{Se}$ and was therefore discarded. The subsequent $1.8 \mathrm{ml}$ were diluted to $18.0 \mathrm{ml}$ with Milli-Q ${ }^{\circledR}$ water and kept for the wet chemical analyses. Concentrations of Se, $\mathrm{Fe}$ and $\mathrm{S}$ in the diluted filtrate were measured by inductively coupled plasma-optical emission spectroscopy (ICP-OES).

\section{X-ray spectroscopy}

After the desired contact time, the Se-treated pyrite samples (chips or powders) were separated from the solution 
bottles for the XRF/XAS measurements. All operations were carried out in the glove box. The polished chips were taken from the Se-solutions with a pair of tweezers and washed with ethanol for a few seconds. Residual ethanol on the surface was eliminated by shortly drying with a tissue. Later tests at the beamline (see section "Selenium sorption") confirmed that this procedure eliminates any measurable trace of dissolved Se from the pyrite surface (which might cause Se-salt precipitation artifacts due to drying). All samples were mounted on a sample holder equipped with a gas inlet and outlet to allow for XRF/XAS measurements under constant inert gas flushing $\left(\mathrm{N}_{2}\right.$ or $\left.\mathrm{He}\right)$ and then transported to the beamline in vacuum desiccators, to prevent oxidation.

The $\mu$-XRF maps and $\mu$-XANES spectra were collected at the micro-XAS beamline, Swiss Light Source (SLS), Switzerland. Measurements were carried out in a special sample holder flushed with inert gas $\left(\mathrm{N}_{2}\right.$ or $\left.\mathrm{He}\right)$ at room temperature, in fluorescence mode, using a single channel Si detector and with a beam size focused to diameters of $\sim 1$ to $5 \mu \mathrm{m}$. Energy calibration was carried out by assigning the value $12,668 \mathrm{eV}$ to the white line of commercial $\mathrm{Na}_{2} \mathrm{Se}^{\mathrm{IV}} \mathrm{O}_{3}$ (following [11]). The $\mu$-XRF maps were generated using the Fmap software provided at the Micro-XAS beamline.

Reference samples of $\mathrm{Na}_{2} \mathrm{Se}^{\mathrm{VI}} \mathrm{O}_{4}, \mathrm{Na}_{2} \mathrm{Se}^{\mathrm{IV}} \mathrm{O}_{3}, \mathrm{Se}^{\mathrm{IV}} \mathrm{O}_{2}$, grey $\mathrm{Se}^{0}$ (Fluka or Sigma-Aldrich) and iron selenide $\left(\mathrm{FeSe}^{-\mathrm{II}}\right.$ ) (Alfa Aesar) were prepared for transmission measurements by diluting with appropriate amounts of boron nitride (BN). XRD data showed that the purchased FeSe contains minor amounts of $\mathrm{Se}^{0}(\sim 6 \mathrm{wt} \%)$. To avoid oxidation, the FeSe reference sample was prepared in the glove box and mounted on the aforementioned sample holder. The other reference samples were not sensitive to oxidation and could therefore be prepared in air. All references and bulk XAS spectra were measured simultaneously in transmission and in fluorescence modes.

In contrast to the polished chips, the pyrite powder samples were measured using a defocused X-ray beam (about $2 \times 2 \mathrm{~mm}$ ) to obtain bulk-XANES spectra. Two pyrite powder samples treated with $\mathrm{Se}^{\mathrm{IV}}(\mathrm{Se}-21 / \mathrm{Se} 22)$ and one treated with $\mathrm{Se}^{\mathrm{VI}}(\mathrm{Se}-23)$ were prepared after 2 months ageing at the $80^{\circ} \mathrm{C}$ by extracting a small portion of Sesorbed pyrite from the solution with a pair of tweezers, absorbing the residual solution with a tissue, introducing the pyrite into a sample holder and finally sealing it with kapton tape in the glove box. The $\mathrm{Se}^{\mathrm{IV}}$ suspensions were subsequently left at room temperature in the glove box during additional 6 months. After this additional ageing time further samples were prepared in the same way in order to record Se K-edge fluorescence EXAFS spectra. These spectra were measured in a cryostat system operated with $\mathrm{N}_{2}$ at $90 \mathrm{~K}$ at the Dutch Belgian Beamline
(DUBBLE), European Synchrotron Radiation Facility (ESRF), in Grenoble, using a 9-channel Ge solid-state detector. The $\mathrm{Si}$ (111) monochromator angle was calibrated by assigning the energy of $11,979 \mathrm{eV}$ to the first inflection point of the K-edge of an $\mathrm{Au}$ metal foil. The reference compounds $\mathrm{Se}^{0}$-grey and $\mathrm{Na}_{2} \mathrm{SeO}_{3}$ were measured in transmission mode with ionization chambers filled with $100 \% \operatorname{Ar}\left(I_{0}\right)$ and a $100 \% \operatorname{Kr}\left(I_{t}\right)$. These reference samples were the same previously measured at the Micro-XAS beamline, thus allowing for careful alignment of XANES spectra obtained at the two beamlines. EXAFS data reduction was performed using the IFEFFIT software package (Athena and Artemis) following standard procedures. The spectra were normalized by fitting a third-degree polynomial. The energy was converted to photoelectron wave vector units $k\left(\AA^{-1}\right)$ by assigning the origin $E_{0}$ to the first inflection point of the absorption edge. Radial Structure Functions (RSF) were obtained by Fourier transformation of the $k^{3}$-weighted $\chi(k)$ function between 3.7 and $12.7 \AA^{-1}$, using a Kaiser-Bessel window and an apodization parameter of 1.0. Fits of the first two shells were performed in real space. Theoretical scattering paths for the fit were calculated with FEFF 8.40 using the structure of trigonal $\mathrm{Se}^{0}$-grey and an automated self-consistency option for potential calculations. The amplitude reduction factor $\left(S_{0}^{2}\right)$ was set to 0.9 based on the method indicated in Koningsberger and Prins [12], using the shake-off probability tables given by Carlson et al. [13].

Because of non-uniform energy calibrations at the various beamlines, systematic $E_{0}$ shifts were applied in order to align the $\mathrm{Se}^{0}$-grey and $\mathrm{Na}_{2} \mathrm{SeO}_{3}$ XANES spectra obtained at Micro-XAS and DUBBLE using the same reference samples and to define a set of energy values consistent with those given by Scheinost et al. [8]. These shifts $(+1.0 \mathrm{eV}$ for DUBBLE data and $-3.4 \mathrm{eV}$ for the Micro-XAS data) were applied systematically to all raw XANES data.

\section{Results}

Overview of wet chemical analyses

A summary of the collected wet chemistry data is given in Table 1. Selenium ICP-OES analyses of the final solutions (data not shown in Table 1) indicated in all cases that only small fractions of the initially dissolved Se were taken up by the pyrite (1-16\%).

Dissolved Fe concentrations (data not shown in Table 1) were mostly below the detection limit and always $<1 \mu \mathrm{M}$. Except for two samples, the dissolved sulfur concentrations of filtrates in contact with NaHS-free solutions were below the detection limit of $\sim 6 \times 10^{-5} \mathrm{M}$. For samples Se-21 
Table 1 Overview of pyrite interaction experiments with $0.01 \mathrm{M} \mathrm{Na}_{2} \mathrm{SeO}_{3}$ and $0.01 \mathrm{M} \mathrm{Na}_{2} \mathrm{SeO}_{4}$ solutions

\begin{tabular}{|c|c|c|c|c|c|c|c|}
\hline Pyrite type & $\begin{array}{l}\text { Initial Se } \\
\text { redox state }\end{array}$ & $\begin{array}{l}\text { Sample } \\
\text { code }\end{array}$ & Ageing time & $\begin{array}{l}\mathrm{pH}_{\min } \\
\left(80^{\circ} \mathrm{C}\right)\end{array}$ & $\begin{array}{l}\mathrm{pH}_{\max } \\
\left(80^{\circ} \mathrm{C}\right)\end{array}$ & $\begin{array}{l}\text { [NaHS] } \\
\mathrm{mM}\end{array}$ & $\begin{array}{l}{[\mathrm{S}]_{\text {final }}} \\
(\mu \mathrm{M})\end{array}$ \\
\hline \multirow[t]{3}{*}{ Powder $<63 \mu \mathrm{m}$ (Huanzala) } & (IV) & $\mathrm{Se}-21$ & $2+6$ months & 8.0 & 8.1 & - & $3.4 \times 10^{2}$ \\
\hline & (IV) & $\mathrm{Se}-22$ & $2+6$ months & 7.9 & 8.0 & 1.0 & $1.17 \times 10^{3}$ \\
\hline & (VI) & $\mathrm{Se}-23$ & 2 months & 4.7 & 8.1 & - & $7 \times 10^{1}$ \\
\hline \multirow[t]{5}{*}{ Polished chips (Navajun) } & (IV) & Se-07 & 2 weeks & 8.0 & 8.0 & - & $<\mathrm{DL}$ \\
\hline & (IV) & Se-08 & 2 months & 8.0 & 8.1 & - & $<\mathrm{DL}$ \\
\hline & (IV) & Se-09 & 2 months & 8.1 & 8.4 & 1.0 & $7.1 \times 10^{2}$ \\
\hline & $(\mathrm{VI})$ & Se-10 & 2 months & 7.9 & 8.3 & - & $<\mathrm{DL}$ \\
\hline & (VI) & Se-11 & 2 months & 8.1 & 8.4 & 1.0 & $4.4 \times 10^{2}$ \\
\hline
\end{tabular}

All experiments were carried out at $80{ }^{\circ} \mathrm{C}$ in a glove box flushed with $\mathrm{N}_{2}\left(5 \mathrm{ppm} \mathrm{O}_{2}\right.$ max). The detection limit (DL) of S concentrations is about $60 \mu \mathrm{M}$

and Se-23, 0.1-0.3 mM dissolved sulfur were detected. This probably indicates the presence of sulfate in solution and hence pyrite oxidation, in spite of the precautions taken to minimize reaction with oxygen. This interpretation is supported for the Se-23 sample by the low $\mathrm{pH}$-values (down to $\mathrm{pH}$ 4.7) measured during the experiment in spite of repeated adjustments with $\mathrm{NaOH}$. For the three NaHSbearing solutions, the ICP-OES data indicate $\sim 100 \% \mathrm{~S}$ recovery in the case of experiment Se-22, whereas significant losses (30 and $60 \%$, respectively) were measured for samples Se-09 and Se-11. A black precipitate, possibly $\mathrm{Se}^{0}$ or $\mathrm{S}^{0}$, was observed in the $\mathrm{Se}-09$ solution.

\section{$\mu$-XRF/XAS and bulk EXAFS experiments}

\section{Reference spectra}

Commercially available $\mathrm{Se}$ compounds $\left(\mathrm{Na}_{2} \mathrm{Se}^{\mathrm{VI}} \mathrm{O}_{4}\right.$, $\mathrm{Na}_{2} \mathrm{Se}^{\mathrm{IV}} \mathrm{O}_{3}, \mathrm{Se}^{\mathrm{IV}} \mathrm{O}_{2}, \mathrm{Se}^{0}$-grey and $\mathrm{FeSe}^{-\mathrm{II}}$ ) were measured as references to discriminate oxidation states based on XANES spectra. In Table 2, the energies obtained for the absorption edges (defined by the maxima of the second derivative) and white lines of the normalized XANES spectra are listed. These values indicate that the oxidized selenium forms $\left(\mathrm{Se}^{\mathrm{IV}, \mathrm{VI}}\right)$ are easily distinguished from the reduced species $\left(\mathrm{Se}^{0,-\mathrm{II}}\right)$ due to the large energy shifts (at least $\left.4.7 \mathrm{eV}\right)$. A distinction is also possible between $\mathrm{Se}^{\mathrm{IV}}$ and $\mathrm{Se}^{\mathrm{VI}}$ (relative edge shift: $2.0 \mathrm{eV}$ ). In contrast, discrimination between $\mathrm{Se}^{0}$ and $\mathrm{Se}^{-\mathrm{II}}$ based on edge or white line positions is difficult considering the small and ill-defined energy shifts of $-1.3 \pm 0.6 \mathrm{eV}$ and $-0.7 \pm 0.6 \mathrm{eV}$, respectively. The large uncertainty is a consequence of the low amplitude of the XANES absorption peak for this compound. Moreover, the position of the $\mathrm{Se}^{-\mathrm{II}}$ edge is known to depend on the neighbouring atoms [6].

Discrimination between $\mathrm{Se}^{0}$ and $\mathrm{Se}^{-\mathrm{II}}$ might be achieved by comparing the normalized heights of the absorption peak maxima (white lines), which is strongly depressed for $\mathrm{FeSe}^{-\mathrm{II}}$. However, this method is ambiguous in spots containing a mixture of $\mathrm{Se}^{\mathrm{IV}}$ and $\mathrm{Se}^{0}$, since linear combinations of the $\mathrm{Se}^{\mathrm{IV}}$ and $\mathrm{Se}^{0}$ reference spectra may produce spectra very similar to that of FeSe. Also, a few spots with very high Se concentrations in the pyrite samples showed depressed absorption peaks due to selfabsorption effects. The situation is further complicated by the possible formation of ferroselite $\left(\mathrm{FeSe}_{2}\right)$. According to recent measurements [14] the Se K-edge energy position of this compound is almost indistinguishable from those of $\mathrm{Se}^{0}$ and $\mathrm{FeSe}$, and the normalized height of the absorption peak is intermediate between these two compounds.

Therefore, at the available energy resolution our XANES spectra are not always able to discriminate between $\mathrm{Se}^{0}, \mathrm{Se}^{-\mathrm{I}}$ and $\mathrm{Se}^{-\mathrm{II}}$ species. Only when both edge position and normalized height of our Se-pyrite sample spectra coincide with those of the $\mathrm{Se}^{0}$-grey reference can lower oxidation states be excluded in the samples (fortunately, this is a frequent case). For some XANES spectra, typically when the normalized height of the absorption peak is low, the $\mathrm{Se}^{0,-\mathrm{I},-\mathrm{II}}$ oxidation

Table 2 Assigned edge $\left(E_{0}\right)$ and white line maxima $\left(E_{\mathrm{w}}\right)$ for the listed reference compounds

\begin{tabular}{llllll}
\hline Reference & Oxidation state & $E_{0}(\mathrm{eV})$ & Shift from Se$^{0}(\mathrm{eV})$ & $E_{\mathrm{w}}(\mathrm{eV})$ & $\mathrm{Shift}_{\text {from Se}}(\mathrm{eV})$ \\
\hline $\mathrm{FeSe}^{*}$ & $-\mathrm{II}$ & $12,654.8 \pm 0.6$ & $-1.3 \pm 0.6$ & $12,657.0 \pm 0.6$ & $-0.7 \pm 0.6$ \\
$\mathrm{Se}^{0}$-grey & 0 & $12,656.1$ & 0 & $12,657.7$ & 0 \\
$\mathrm{Na}_{2} \mathrm{SeO}_{3}$ & $+\mathrm{IV}$ & $12,660.8$ & +4.7 & $12,662.4$ & +4.7 \\
$\mathrm{Na}_{2} \mathrm{SeO}_{4}$ & + VI & $12,662.8$ & +6.7 & $12,665.3$ & +7.6 \\
\hline
\end{tabular}

* Edge and white line positions of FeSe cannot be determined with precision due to the low edge-step amplitude and the broad white line peak 
states cannot be distinguished, in which case we will use the generic notation $\mathrm{Se}^{\text {red }}$ instead of explicit oxidation numbers.

\section{Experiments with $S e^{I V}$}

The $\mu$-XRF maps reveal a highly heterogeneous Se distribution on the pyrite surface after interaction with $\mathrm{Na}_{2} \mathrm{SeO}_{3}$ solution during 2 weeks or 2 months. In each studied sample in contact with $\mathrm{Se}^{\mathrm{IV}}$ bearing solutions, highlyconcentrated Se clusters of a few $\mu \mathrm{m}$ size were detected, surrounded by areas with lower and uniform Se concentration (Figs. 1, 2).

Figure 3 shows the $\mu$-XANES of the spots labeled in Figs. 1 and 2 and the XANES of the reference compounds. The spectra obtained for the two concentrated spots after 2 weeks interaction (Fig. 2) differed considerably, indicating that spot 5 was dominated by $\mathrm{Se}^{\mathrm{IV}}$, whereas spot 6 represented a mixture of $\mathrm{Se}^{\text {red }}$ and $\mathrm{Se}^{\mathrm{IV}}$, with a high proportion of reduced species. Similar mixed oxidation state spots were found in other areas of this sample. In the sample aged during 2 months, the large majority of the $\mu$-XANES spectra indicated the presence of only $\mathrm{Se}^{\text {red }}$. Occasionally spots indicating a minor proportion of $\mathrm{Se}^{\mathrm{IV}}$ were found. The coexistence of $\mathrm{Se}^{\mathrm{IV}}$ and $\mathrm{Se}^{\text {red }}$ in the same spots suggests a sequential mechanism by which selenium is first adsorbed as $\mathrm{Se}^{\mathrm{IV}}$ and subsequently reduced in situ on the pyrite surface.

The progressive reduction of the sorbed selenium was confirmed by the results obtained for $\mathrm{Se}^{\mathrm{IV}}$-treated pyrite powder measured after 2 and 8 months ageing time. The bulk XANES spectrum of the Se-21 sample after interaction with $\mathrm{Na}_{2} \mathrm{SeO}_{3}$ solution during 2 months at $80{ }^{\circ} \mathrm{C}$ is consistent with a mixture of about $50 \mathrm{~mol} \% \mathrm{Se}^{\mathrm{IV}}$ and 50 mol.\% $\mathrm{Se}^{0}$ (Fig. 4, circles).

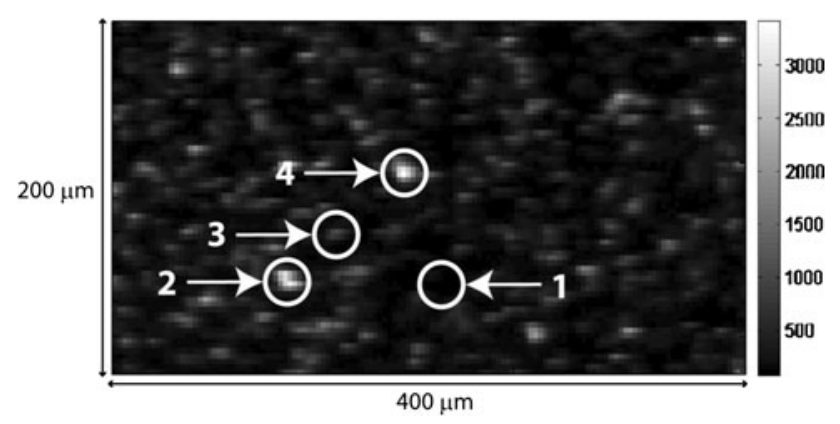

Fig. 1 Micro-XRF map of the Se-K $\alpha$ signal for a polished pyrite chip (sample Se-08) reacted during 2 months with $\mathrm{Na}_{2} \mathrm{SeO}_{3}$ solution under anoxic conditions, showing the location of $\mu$-XANES collection spots (labeled 1-4). The beam diameter was $\sim 2 \mu \mathrm{m}$ and the pixel size $3 \mu \mathrm{m} \times 3 \mu \mathrm{m}$. The intensity scale gives the detector response in counts per seconds
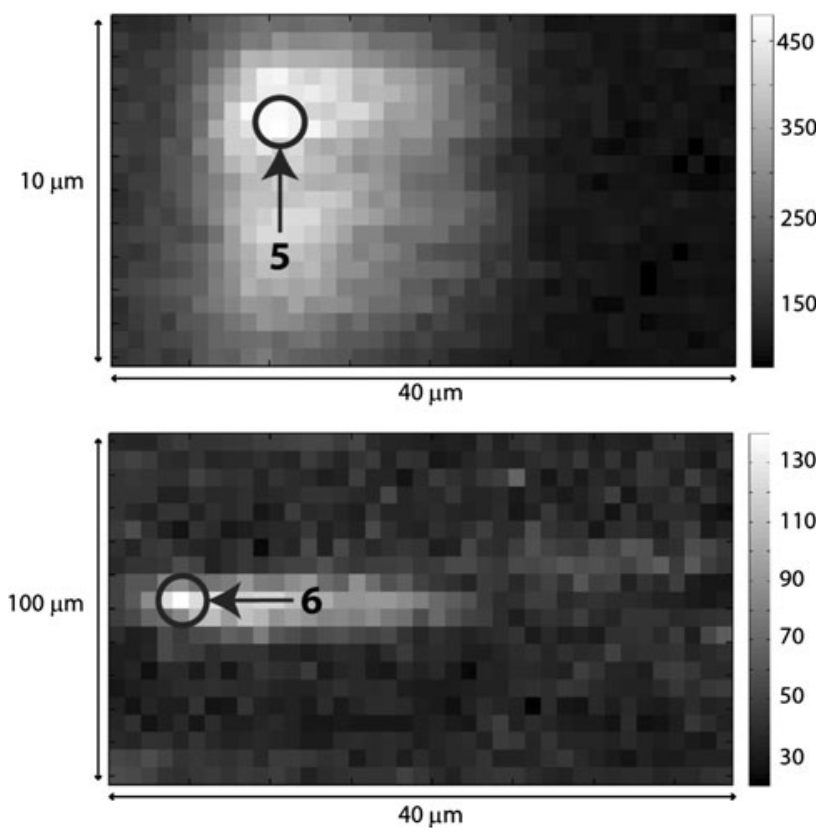

Fig. 2 Micro-XRF elemental maps of the $\mathrm{Se}-\mathrm{K} \alpha$ signal for the polished pyrite chip reacted during 2 weeks with $\mathrm{Na}_{2} \mathrm{SeO}_{3}$ solution under anoxic conditions (sample Se-07). Selected analyzed $\mu$-XANES spots are encircled. The beam diameter was $\sim 2 \mu \mathrm{m}$ and the pixel size $3 \mu \mathrm{m} \times 3 \mu \mathrm{m}$. The intensity scale gives the detector response in counts per seconds

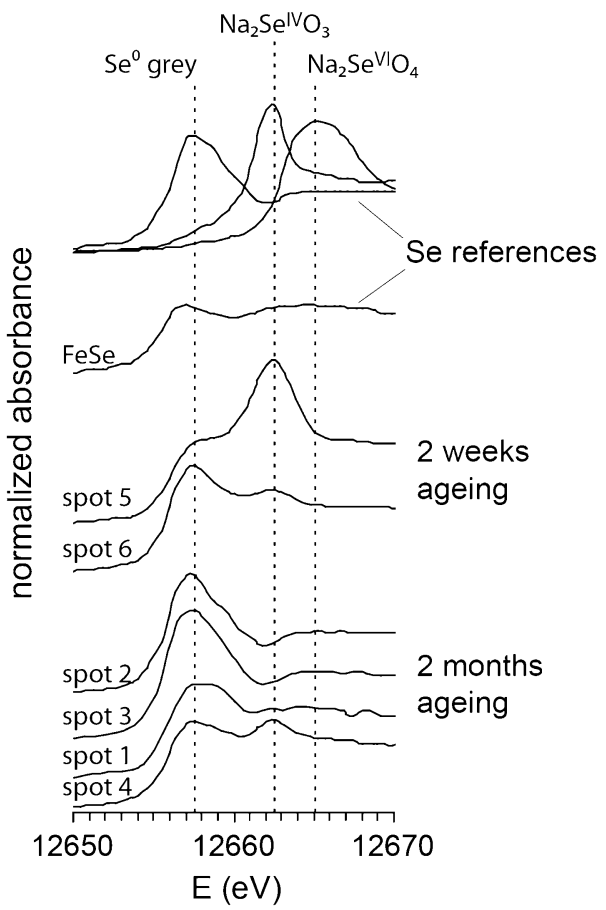

Fig. 3 Se K-edge $\mu$-XANES of selected spots (labeled in Figs. 1, 2) from pyrite chips treated with $\mathrm{Na}_{2} \mathrm{SeO}_{3}$ solutions, compared to the XANES spectra of reference compounds for $\mathrm{Se}^{-\mathrm{II}}, \mathrm{Se}^{0}, \mathrm{Se}^{\mathrm{IV}}$ and $\mathrm{Se}^{\mathrm{VI}}$ 


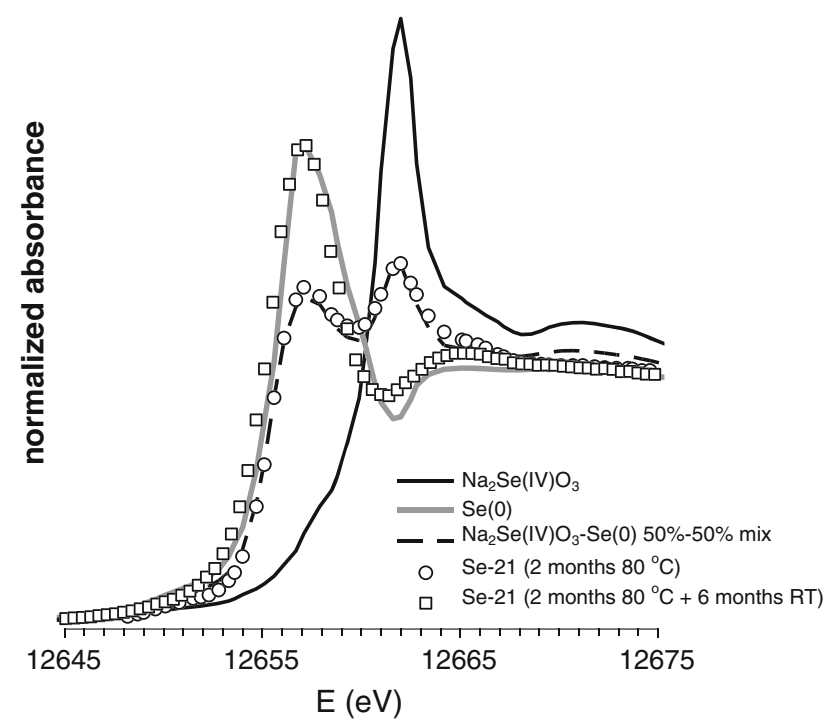

Fig. 4 Bulk XANES of pyrite powder (sample Se-21) treated with $\mathrm{Na}_{2} \mathrm{SeO}_{3}$ solution during 2 months at $80{ }^{\circ} \mathrm{C}$ and after additional 6 months ageing at room temperature (RT). The normalized Se-pyrite spectra are superimposed on the spectra of pure $\mathrm{Se}^{0}$, of pure $\mathrm{Na}_{2} \mathrm{SeO}_{3}$ and of an equimolar mixture of the two reference compounds

After additional 6 months ageing time in the glove box at room temperature, complete reduction to $\mathrm{Se}^{0}$ was observed (Fig. 4, squares), which was confirmed by the EXAFS analysis of the same sample (Se-21 after 8 months total ageing time) summarized in Fig. 5 and Table 3.

For the $\mathrm{Se}^{0}$ reference, the Radial Structure Function (RSF) showed a major peak at $\mathrm{R}+\Delta \mathrm{R} \sim 2.3 \AA$, and a minor peak at $\mathrm{R}+\Delta \mathrm{R} \sim 3.2 \AA$, which could be fitted assuming the presence of two $\mathrm{Se}-\mathrm{Se}$ shells (Table 3). The $\mathrm{CN}$ of 2.14 was close to the expected value of 2. Further peaks were very weak and could not be fitted satisfactorily.

The EXAFS spectrum and derived fit parameters of the Se-treated pyrite were very similar to those of the $\mathrm{Se}^{0}$ reference. Also in this case, a satisfactory fit was obtained assuming two $\mathrm{Se}-\mathrm{Se}$ shells. The interatomic distances (R) determined for the pyrite sample and the $\mathrm{Se}^{0}$ reference were identical within experimental uncertainties, but the corresponding coordination numbers $(\mathrm{N})$ differed. In particular, $\mathrm{N}_{\mathrm{Se}-\mathrm{Se} 1}$ for the Se-treated pyrite indicated three neighbouring atoms at $\sim 2.38 \AA$ instead of the two expected in most crystalline $\mathrm{Se}^{0}$ polymorphs. Additionally, the value of $\mathrm{N}_{\mathrm{Se}-\mathrm{Se} 2}$ was lower than expected, which could indicate structural disorder.

In order to test for the possible formation of a solid solution with pyrite or of isolated Se complexes on the pyrite surface, we attempted fits assuming $\mathrm{Se}-\mathrm{Fe}$ or $\mathrm{Se}-\mathrm{O}$ shells and using $\mathrm{FeSe}$ or $\mathrm{Na}_{2} \mathrm{SeO}_{3}$, respectively, as models for FEFF8 calculations. Any attempt to fit the spectrum of the Se-pyrite sample with the mentioned alternative models was unsuccessful. Formation of pure metallic Se on the pyrite surface is therefore conclusively proven by our EXAFS analysis, whereas no evidence was found that Se sorbed on the Se-21 sample did form a solid solution with pyrite or surface complexes, nor a separate $\mathrm{Fe}-\mathrm{Se}$ or $\mathrm{Se}^{\mathrm{IV}, \mathrm{VI}}$ oxide phase. These alternative $\mathrm{Se}$ species, if they exist in sample Se-21, must be present in minor amounts.

All attempts to fit our data starting from other $\mathrm{Se}^{0}$ structural models led to comparable results. The differentiation between various $\mathrm{Se}^{0}$ polymorphs was therefore not possible. Scheinost et al. [8] studied EXAFS spectra of various Se reference compounds, including an amorphous red $\mathrm{Se}^{0}$ phase, a crystalline red $\mathrm{Se}^{0}$ phase and a trigonal grey $\mathrm{Se}^{0}$ phase. Their fitted $\mathrm{N}$ and $\mathrm{R}$ values for the first $\mathrm{Se}-\mathrm{Se}$ shell did not significantly vary among the different compounds. However, their fits of the second Se-Se shell yielded for the red $\mathrm{Se}^{0}$ compounds longer interatomic distances $(\mathrm{R}+\Delta \mathrm{R} \sim 3.7 \AA)$ than for the $\mathrm{Se}^{0}$-grey reference $(\mathrm{R}+\Delta \mathrm{R} \sim 3.4 \AA)$. Our $\mathrm{Se}^{0}$-grey reference material also yielded $\mathrm{R}+\Delta \mathrm{R} \sim 3.4 \AA$ for the second shell, although with a lower coordination number $(\mathrm{N} \sim 2.6)$ than that found by Scheinost et al. [8] $(\mathrm{N} \sim 4)$. Based on the high precision of the interatomic distances and considering that coordination numbers determined by EXAFS are frequently inaccurate, we conclude that the Se sorbed on the $\mathrm{Se}-21$ pyrite sample was also trigonal grey $\mathrm{Se}^{0}$.
Fig. 5 Se K-edge spectra of $\mathrm{Se}^{0}$-grey reference material and of Se sorbed onto pyrite (sample Se-21 after 8 months ageing time): $k^{3}$-weighted normalized spectra (left) and corresponding Fourier Transforms (right)
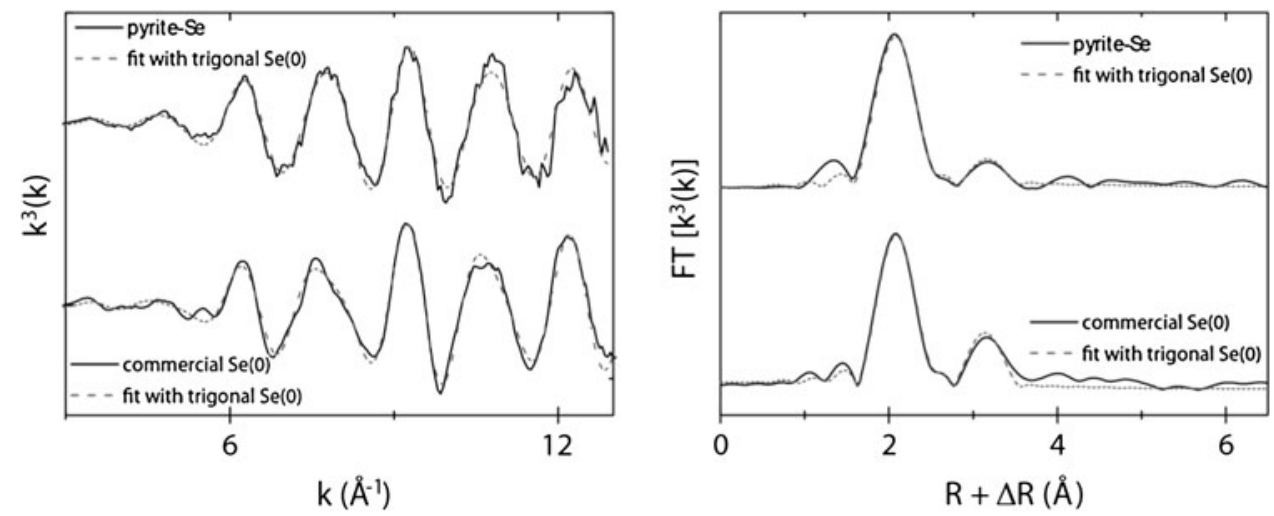
Table 3 EXAFS fit results of Se sorbed onto pyrite after 8 months ageing time (sample Se-21), showing coordination numbers (N), interatomic distances (R), Debye-Waller factors (DW), energy shift $\left(\Delta E_{0}\right)$ and the R-factor

\begin{tabular}{lllllllll}
\hline Sample & $\mathrm{N}_{\mathrm{Se}-\mathrm{Se} 1}$ & $\mathrm{R}_{\mathrm{Se}-\mathrm{Se} 1}(\AA)$ & $\mathrm{DW}\left(\AA^{2}\right)$ & $\mathrm{N}_{\mathrm{Se}-\mathrm{Se} 2}$ & $\mathrm{R}_{\mathrm{Se}-\mathrm{Se} 2}(\AA)$ & $\mathrm{DW}\left(\AA^{2}\right)$ & $\Delta E_{0}(\mathrm{eV})$ & $\mathrm{R}-\mathrm{factor}$ \\
\hline $\mathrm{Se}^{\mathrm{a}}$ (grey) reference & $2.1 \pm 0.2$ & $2.39 \pm 0.01$ & 0.003 & $2.6 \pm 0.3$ & $3.41 \pm 0.01$ & $0.005^{\mathrm{b}}$ & $6.1 \pm 1.2$ & 0.01 \\
Se sorbed onto pyrite & $3.2 \pm 0.3$ & $2.38 \pm 0.01$ & 0.004 & $1.3 \pm 0.4$ & $3.41 \pm 0.02$ & $0.005^{\mathrm{b}}$ & $7.2 \pm 1.3$ & 0.01 \\
\hline
\end{tabular}

${ }^{a}$ R-factor from Artemis code

b Fixed parameter

\section{Experiments with $S e^{V I}$}

The $\mu$-XRF maps recorded on pyrite chips treated with $\mathrm{Na}_{2} \mathrm{Se}^{\mathrm{VI}} \mathrm{O}_{4}$ solution during 2 months at $80{ }^{\circ} \mathrm{C}$ revealed a highly heterogeneous Se uptake, with distribution patterns very similar to those observed for the $\mathrm{Se}^{\mathrm{IV}}$-treated pyrites. In each studied sample in contact with $\mathrm{Se}^{\mathrm{VI}}$ bearing solutions highly concentrated Se clusters of a few $\mu \mathrm{m}$ size were detected surrounded by areas with lower and uniform Se concentration, yielding $\mu$-XRF maps (Fig. 6) very similar to those obtained after interaction with $\mathrm{Na}_{2} \mathrm{Se}^{\mathrm{IV}} \mathrm{O}_{3}$ solution.

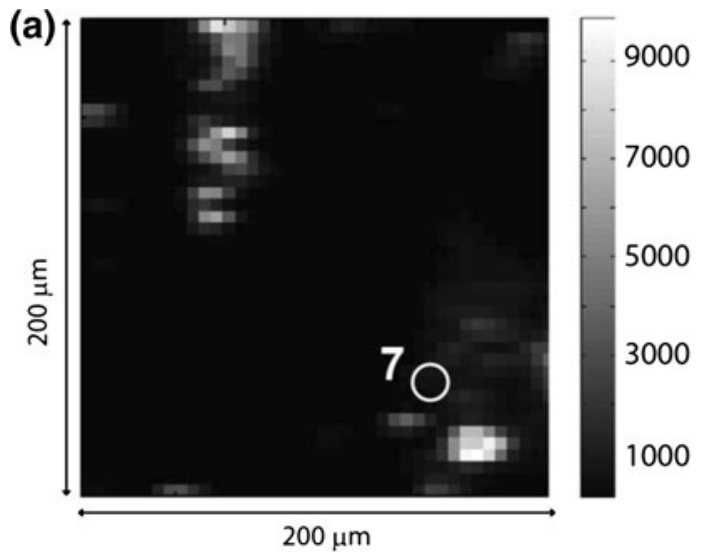

(b)

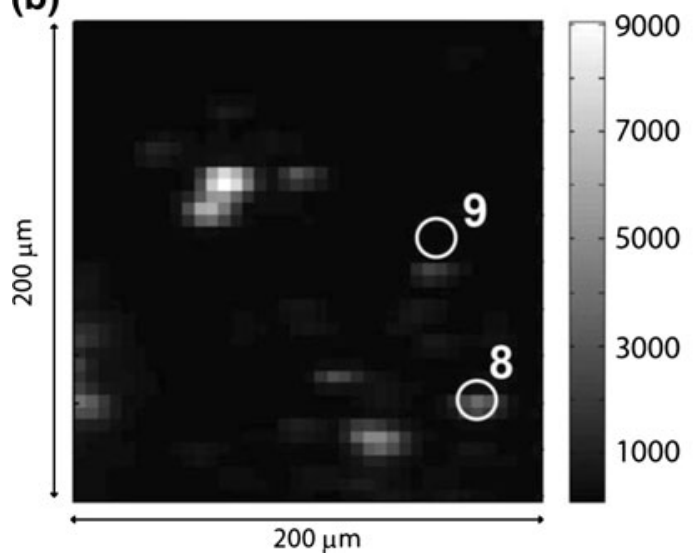

Fig. 6 Micro-XRF map of the $\mathrm{Se}-\mathrm{K} \alpha$ signal from polished pyrite chips (a, b: sample Se-10; c: sample Se-11) reacted during 2 months with $\mathrm{Na}_{2} \mathrm{SeO}_{4}$ solution under anoxic conditions, showing the location
Figure 7 shows the Se K-edge XANES of a pyrite powder (Se-23) and the $\mu$-XANES of selected spots from two pyrite chips (Se-10, Se-11) treated with $\mathrm{Na}_{2} \mathrm{Se}^{\mathrm{VI}} \mathrm{O}_{4}$ ( \pm NaHS $)$ solutions, compared to the XANES spectra of Se reference compounds. In contrast to the measurements carried out with $\mathrm{Se}^{\mathrm{IV}}$-treated samples, photoreduction was frequently observed during the XANES data collection, but only for the sample treated with NaHS-bearing solution (Se-11). In such cases, each successive scan showed an increasing component of $\mathrm{Se}^{\text {red }}$ with simultaneously decreasing contribution of $\mathrm{Se}^{\mathrm{VI}}$. In contrast, the spectra from the pyrite sample treated with NaHS-free

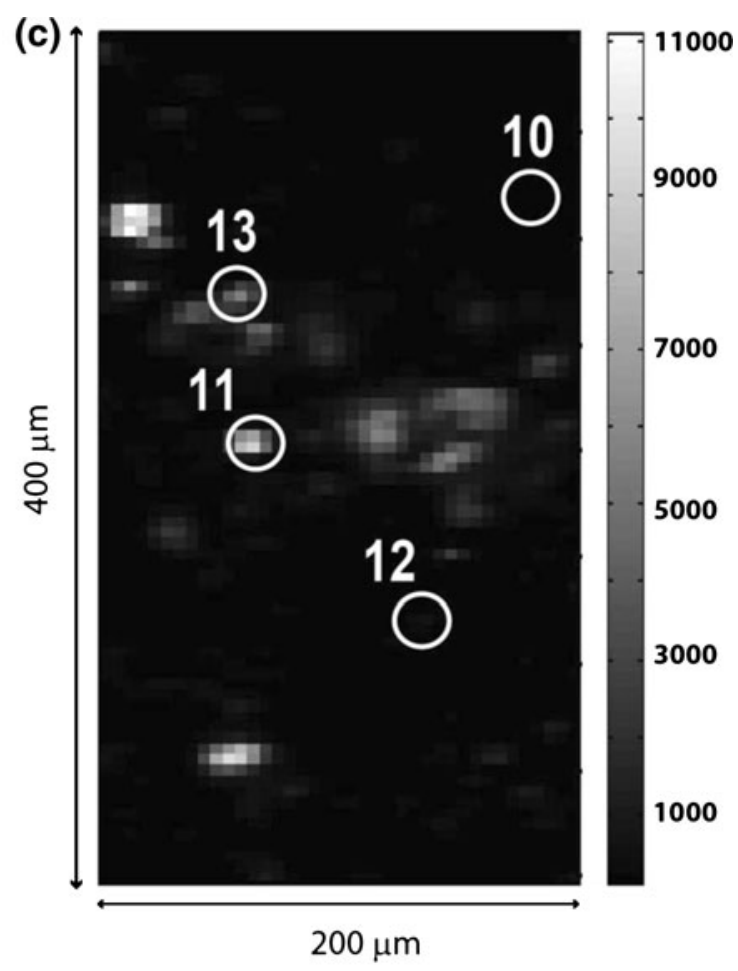

of $\mu$-XANES collection spots (labeled 7-13). The beam diameter was $\sim 2 \mu \mathrm{m}$ and the pixel size $5 \mu \mathrm{m} \times 5 \mu \mathrm{m}$. The intensity scale gives the detector response in counts per seconds 
$\mathrm{Se}^{\mathrm{VI}}$-solution (Se-10) remained stable. In Fig. 7, we included for sample Se-11 only $\mu$-XANES spectra that remained unaffected with increasing collection time. We suspect that the observed photoreduction may be due to the presence of hydrogen sulfide adsorbed on the pyrite surface, owing to the mild washing procedure adopted. Under the X-ray beam, this residual hydrogen sulfide may have acted as a reductant of $\mathrm{Se}^{\mathrm{VI}}$ sorbed on the pyrite surface.

An inspection of Fig. 7 shows the coexistence of both oxidized and reduced Se species at the same location, similarly to the $\mathrm{Se}^{\mathrm{IV}}$-treated pyrites. Nevertheless, the majority of the recorded $\mu$-XANES spectra, including a number of them not included in Fig. 7, is dominated by $\mathrm{Se}^{\text {red }}$. Only a few of the collected $\mu$-XANES spectra show the presence of $\mathrm{Se}^{\mathrm{IV}}$ (spot 7) or $\mathrm{Se}^{\mathrm{VI}}$ (spot 10 and spot 13).

The bulk XANES spectrum recorded on Huanzala pyrite powder (Se-23) shows a quite different picture, clearly indicating a predominance of both oxidized species $\mathrm{Se}^{\mathrm{IV}}$ and $\mathrm{Se}^{\mathrm{VI}}$ with only a minor component of reduced $\mathrm{Se}$ species. This spectrum suggests that Se uptake proceeded via sorption of $\mathrm{Se}^{\mathrm{VI}}$, followed by subsequent reduction to $\mathrm{Se}^{\mathrm{IV}}$ and finally to $\mathrm{Se}^{\text {red }}$. After 2 months ageing, only a small proportion of the Se was reduced. In summary, our data indicate that at $80^{\circ} \mathrm{C} \mathrm{Se}^{\mathrm{VI}}$ can also be reduced in the presence of pyrite, although the rate of reduction may have been slower than for the $\mathrm{Se}^{\mathrm{IV}}$-treated pyrites.

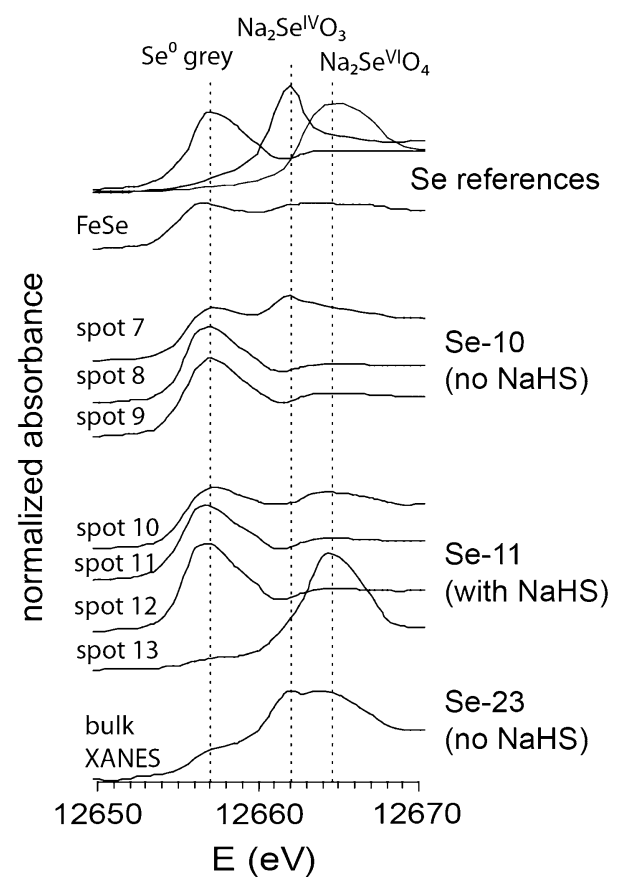

Fig. 7 Se K-edge XANES of a pyrite powder (Se-23) and $\mu$-XANES of selected spots from pyrite chips (Se-10, Se-11) treated with $\mathrm{Na}_{2} \mathrm{Se}^{\mathrm{VI}} \mathrm{O}_{4}$ solutions, compared to the XANES spectra of reference compounds for $\mathrm{Se}^{-\mathrm{II}}, \mathrm{Se}^{0}, \mathrm{Se}^{\mathrm{IV}}$ and $\mathrm{Se}^{\mathrm{VI}}$

\section{Discussion}

Thermodynamic stability

Pourbaix diagrams for the $\mathrm{S}-\mathrm{Fe}-\mathrm{O}-\mathrm{H}$ system and for the $\mathrm{Se}-\mathrm{O}-\mathrm{H}$ systems were computed using the software PhreePlot (beta version, http://www.phreeplot.org/), which is based on the geochemical speciation code PHREEQC (Fig. 8). Total S and Fe concentrations were fixed at values approaching those calculated or measured in our systems $\left([\mathrm{S}]_{\mathrm{tot}}=5 \mu \mathrm{M}\right.$ and $\left.[\mathrm{Se}]_{\mathrm{tot}}=0.01 \mathrm{M}\right)$. Underlying thermodynamic data were taken from the Nagra-PSI 01/01 database [15] except for selenium, for which the data selected in Olin et al. [16] were used. The diagrams were calculated at $25{ }^{\circ} \mathrm{C}(1 \mathrm{bar})$ because many of the required data cannot be consistently extrapolated to the temperatures of the batch experiments $\left(\mathrm{T}=80^{\circ} \mathrm{C}\right)$.

The diagrams show that, provided no Fe-Se solid phases form (e.g. FeSe, $\mathrm{FeSe}_{2}$ or a solid solution with pyrite), the expected coexisting stable phases under reducing conditions are pyrite and $\mathrm{Se}^{0}$. Although this result is consistent with the observations, oxidation of pyrite in aqueous media is frequent even in laboratory tests performed at trace levels of $\mathrm{O}_{2}$ [17]. For instance, a moderate drop in $\mathrm{pH}$ was observed in pyrite-iodide experiments carried out under similar conditions [18]. Our experiments with pyrite powders (Se-21, Se-23) also suggest oxidation of pyrite in the glove-box atmosphere. On the other hand, due to the high pyrite:solution ratio (4-16 g/l), only a very limited fraction of the exposed mineral surface could have been affected by the oxidation process. The large excess of pyrite ensures that the Eh-pH conditions at the mineral surface remain within the grey-shaded field in Fig. 8b. Thus, in spite of thermodynamic disequilibrium between the $\left(\mathrm{O}_{2}\right.$-bearing $)$ $\mathrm{N}_{2}$ gas in the glove box and solid phase, the Eh-pH conditions of the solution in contact with the mineral surface are buffered by pyrite. Dissolved oxygen coming in contact with pyrite will lead to oxidation, but since the amount of oxygen available is small compared to that of pyrite, only a minor fraction of the mineral surface will be affected. Under such conditions, and provided that no solid solution between $\mathrm{Fe}$ selenide and $\mathrm{Fe}$ sulfide forms, the predicted thermodynamic stable Se species in our system is metallic selenium, which is consistent with our observation.

Selenium sorption

Although the observed surface precipitation of sparingly soluble reduced $\mathrm{Se}$ is in agreement with thermodynamic predictions, the explanation of the mechanisms leading to surface adsorption of the anionic dissolved $\mathrm{Se}^{\mathrm{IV}, \mathrm{VI}}$ species, which is a necessary intermediate step required for the formation of $\mathrm{Se}^{\text {red }}$ on the pyrite surface, is not trivial, since 
Fig. 8 Eh-pH diagrams at $25{ }^{\circ} \mathrm{C}$ for a the $\mathrm{S}-\mathrm{Fe}-\mathrm{O}-\mathrm{H}$ system with total $\mathrm{Fe}=10^{-6} \mathrm{M}$ and total $\mathrm{S}=5 \times 10^{-6} \mathrm{M}$, b $\mathrm{Se}-\mathrm{O}-\mathrm{H}$ with total $\mathrm{Se}=10^{-2} \mathrm{M}$. On $\mathbf{b}$ the stability field of pyrite from $\mathbf{a}$ is superimposed as shaded area
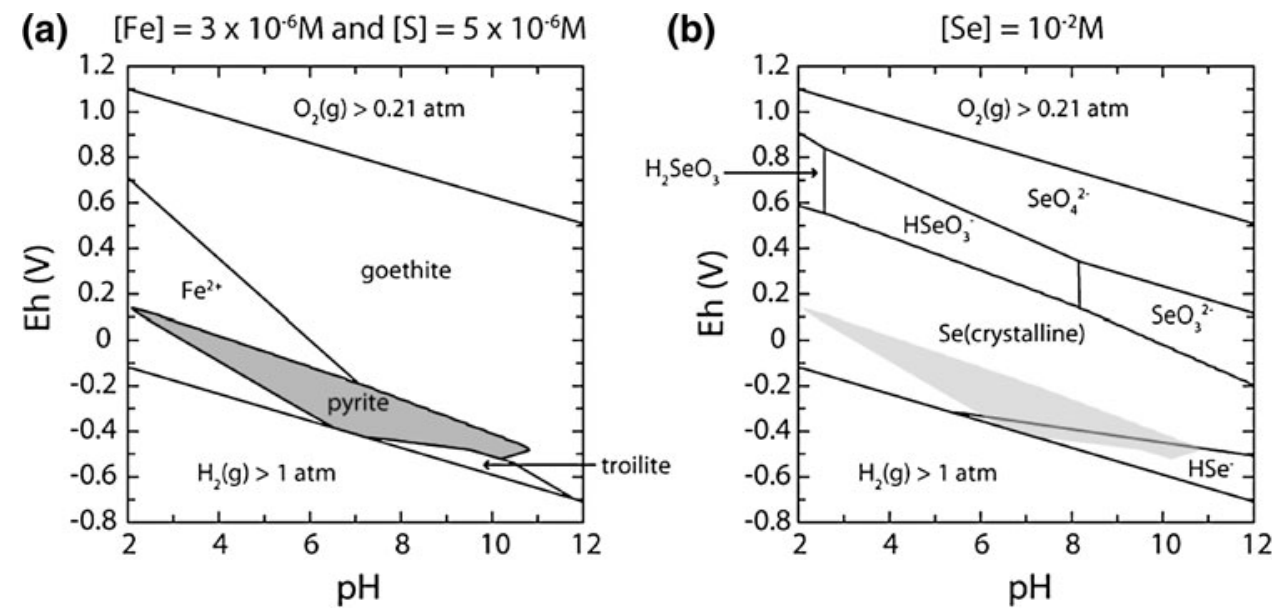

the pyrite surface is negatively charged at $\mathrm{pH} \sim 8$. Our $\mu$-XANES results showed however without any doubt that in some cases $\mathrm{Se}^{\mathrm{IV}}$ and/or $\mathrm{Se}^{\mathrm{VI}}$ coexist, at least transiently, with $\mathrm{Se}^{\text {red }}$ at the same location. We can exclude artifacts due to incomplete washing of the solution, since $\mu$-XRF maps of pyrite immersed shortly $(<1 \mathrm{~min})$ in $0.01 \mathrm{M}$ $\mathrm{Na}_{2} \mathrm{SeO}_{3}$ solution and then briefly washed with ethanol in the same way as the samples, showed only background $\mathrm{Se}$ $\mathrm{K} \alpha$ signals. Thus, the presence of $\mathrm{Se}^{\mathrm{IV}, \mathrm{VI}}$ on the pyrite surface indicates that sorption of these species indeed occurred. Similar results were obtained in batch experiments at lower concentrations $\left(10^{-6} \mathrm{M}\right.$ total $\left.\mathrm{Se}\right)$, by Bruggeman et al. [5] who studied ${ }^{75} \mathrm{Se}^{\mathrm{IV}}$ radiotracer uptake by a natural pyrite powder in a synthetic clay water. After 7 days of equilibration, $\mathrm{R}_{\mathrm{d}}$ values varying from $\sim 0.1$ to $\sim 10 \mathrm{~m}^{3} / \mathrm{kg}$ were determined. After 2 months ageing, bulk EXAFS on powder samples showed that the Se sorbed on the pyrite from a $\mathrm{Se}^{\mathrm{IV}}$ solution was completely reduced to the metallic state, probably in the form of trigonal (grey) $\mathrm{Se}^{0}$.

In analogy with the results obtained on iodide uptake on pyrite [18], one could assume that the cluster-like distribution of $\mathrm{Se}$ in the $\mu$-XRF maps reflects adsorption of the dissolved $\mathrm{SeO}_{3}{ }^{2-}$ and $\mathrm{SeO}_{4}{ }^{2-}$ on the oxidized parts of the pyrite surface. Such regions are probably similar to ferric oxy-hydroxides $\left(\mathrm{pH}_{\mathrm{PZC}}>8\right.$, see [19]) and thus positively charged at $\mathrm{pH} \sim 8$, offering suitable surface sites for outer-sphere complexation of oxy-anions. According to this model, Se uptake would take place only on minor patches of the exposed pyrite that have undergone surface oxidation, due to the trace amounts of $\mathrm{O}_{2}$ present in the solution prepared under quasi-anoxic conditions. The negatively charged part of the surface would remain free of sorbed Se. However, this interpretation, although appealing, can hardly explain the considerable amounts of Se (up to $16 \%$ of the initially dissolved $\mathrm{Se}$ ) sorbed on the pyrite surface. Indeed, a simple outer or inner-sphere adsorption process can be ruled out for the high-intensity spots, since the very high $\mathrm{Se}-\mathrm{K} \alpha$ counting rates and the anticorrelation with the $\mathrm{Fe}-\mathrm{K} \alpha$ signal (maps not shown) indicate formation of surface precipitates of reduced Se (probably $\mathrm{Se}^{0}$-grey, as indicated by the bulk EXAFS data) rather than of a monolayer of adsorbed Se. Moreover, the diffuse low intensity regions between such spots (black to dark grey in Figs. 1, 2, 6) are not Se-free, as shown by detector counting rates of up to $\sim 1,000 \mathrm{cps}$. Thus, in spite of the very heterogeneous distribution, Se appears to have been taken up over the entire pyrite surface. The nature of Se in the diffuse low-intensity region is not clear. It cannot be exclu$\mathrm{ded}$, that $\mathrm{Fe}(\mathrm{S}, \mathrm{Se})_{2}$ solid solution was formed there.

In spite of the aforementioned unresolved issues, our data indicate without any doubt that also selenate (not only selenite) was sorbed and then progressively reduced. This process apparently proceeded via an intermediate stage as $\mathrm{Se}^{\mathrm{IV}}$, as indicated by the bulk XANES of the Se-23 sample, where at least three redox states $\left(\mathrm{Se}^{\text {red }}, \mathrm{Se}^{\mathrm{IV}}\right.$ and $\left.\mathrm{Se}^{\mathrm{VI}}\right)$ were found to coexist. Reduction of selenate has been observed in experiments carried out in contact with FeS under quasianoxic conditions [20], green rust [21] and recently a pyrite-greygite nanocomposite [14]. The evidence emerging from the present and the cited studies is that both selenite and selenate are readily reduced even at low temperature in the presence of $\mathrm{Fe}^{\mathrm{II}}$-sulfides and other $\mathrm{Fe}^{\mathrm{II}}$ bearing minerals.

In the view of the available knowledge on the geochemical cycle of Se, these results are not surprising. As pointed out by Stanton [22] the redox behavior of selenium in geochemical systems is quite different from that of sulfur, in spite of the reciprocal affinity of these two elements. Whereas dissolved sulfate is ubiquitous in nearsurface environments (e.g. ocean water), only trace amounts of dissolved selenium are usually found in natural waters [23], indicating that $\mathrm{Se}^{\mathrm{VI}}$ and $\mathrm{Se}^{\mathrm{IV}}$ are more easily reduced to insoluble solids than the corresponding sulfur 
species. Indeed, most of the natural Se in the earth crust is found as minor component in sulfides and only a few selenite/selenate minerals exist, which are stable only under exceptional conditions [24]. This fact is also reflected in the higher standard reduction potentials of Se redox couples compared to the corresponding $S$ couples [25].

The behavior of $\mathrm{Se}$ in the geochemical cycle has important consequences on the fate of the long-lived radionuclide ${ }^{79} \mathrm{Se}$ when released to aqueous solutions from corroding radioactive waste. In most safety analyses of radioactive waste disposal sites ${ }^{79} \mathrm{Se}$ is considered to be transported in aqueous media as soluble selenite/selenate, leading to a high contribution of this nuclide to the calculated radiological dose [2]. This assumption is in line with the fact that ${ }^{79} \mathrm{Se}$ in radioactive waste is mainly present in oxidized form. For instance, Se is present as $100 \% \mathrm{Se}^{\mathrm{IV}}$ in the simulated vitrified waste denoted MW [26] (Fig. 9) and will therefore be released as selenite upon aqueous corrosion. However, in the light of the present results, the global-scale geochemical evidence and considering the highly reducing conditions that will prevail in the repository environment (e.g. buffered by steel/copper canisters), there is little doubt that ${ }^{79} \mathrm{Se}$ will be readily reduced to insoluble $\mathrm{Se}^{\text {red }}$ forms before it can reach the biosphere. This is also indicated by kinetic sorption tests of $\mathrm{Se}^{\mathrm{IV}}$ on clay rocks, which clearly show higher $\mathrm{R}_{\mathrm{d}}$-values under anaerobic conditions compared to similar tests conducted in air [27]. Therefore, the assumption made in safety analyses that ${ }^{79} \mathrm{Se}$ will migrate as soluble oxidized nuclide seems to be exceedingly conservative.

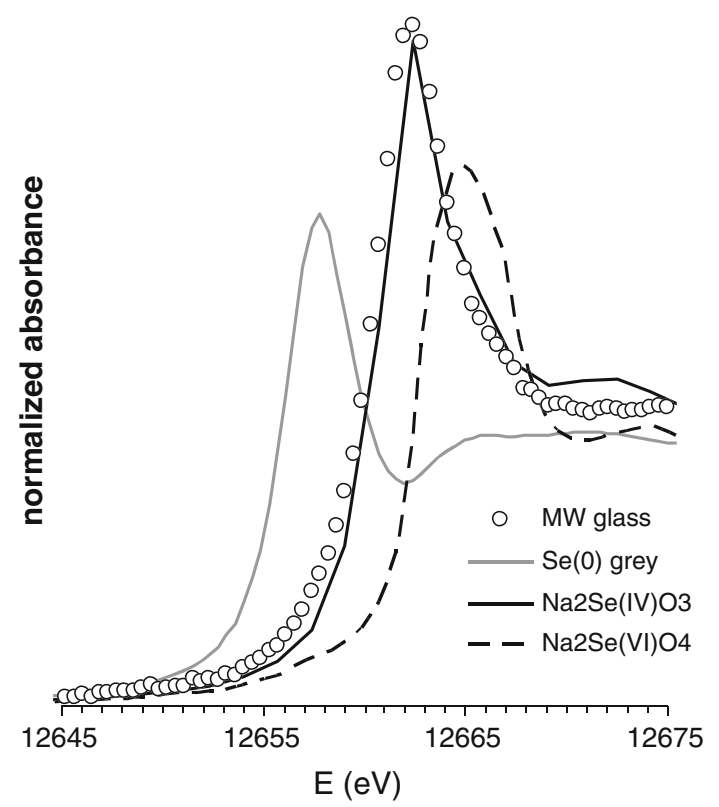

Fig. 9 XANES spectrum of a vitrified radioactive waste simulate (MW), compared to the spectra of reference compounds for $\mathrm{Se}^{0}, \mathrm{Se}^{\mathrm{IV}}$ and $\mathrm{Se}^{\mathrm{VI}}$

\section{Conclusion}

Batch experiments at $\mathrm{pH} \sim 8$ and $80{ }^{\circ} \mathrm{C}$ showed that dissolved selenite and selenate are sorbed and subsequently reduced to insoluble forms (at least partly as $\mathrm{Se}^{0}$ ) on the surface of natural pyrite in the time scale of weeks to months. The Se sorbed on the pyrite is distributed heterogeneously on the mineral surface and forms micrometer-sized clustered surface precipitates, surrounded by homogeneous regions with lower, but still elevated Se-concentration. In most cases, $\mu$-XANES data indicate reduction to $\mathrm{Se}^{0}$, although further reduction to $\mathrm{Se}^{-\mathrm{I},-\mathrm{II}}$ cannot always be excluded. Evidence was found for locations where reduced Se coexists with $\mathrm{Se}^{\mathrm{IV}}$ and/or $\mathrm{Se}^{\mathrm{VI}}$. In a few cases, contributions from all three species were found, suggesting the stepwise reduction $\mathrm{Se}^{\mathrm{VI}} \geq \mathrm{Se}^{\mathrm{IV}} \geq$ reduced $\mathrm{Se}$. In two cases, bulk EXAFS analyses of pyrite powder reacted with $\mathrm{Na}_{2} \mathrm{Se}^{\mathrm{IV}} \mathrm{O}_{3}$ solution allowed us to identify ordered $\mathrm{Se}^{0}$ grey phase as the endproduct of the reduction process (after 8 months ageing time).

Thermodynamic models, though possibly incomplete because of the lack of Fe-Se phases, were in good agreement with spectroscopic results. According to the calculated Pourbaix diagrams $\mathrm{Se}^{\mathrm{IV}, \mathrm{VI}}$ should indeed be reduced to crystalline, sparingly soluble $\mathrm{Se}^{0}$ at equilibrium with pyrite. Owing to reductive sorption on pyrite, the migration of long-lived ${ }^{79} \mathrm{Se}$ released as oxidized oxo-anion (selenite/ selenate) from vitrified waste or spent fuel may be significantly retarded under repository conditions.

Acknowledgments The beamline scientists at the Micro-XAS beamline at the Swiss Light Source (Dr. D. Grolimund, Dr. C. Borca) and at the DUBBLE beamline at ESRF (Dr. S. Nikitenko) are warmly thanked for the experimental assistance during the synchrotron-based investigations. Many thanks are due to B. Meyer from the Micro-XAS team for developing a sample holder allowing anoxic measurements. We are also indebted to Dr. Rainer Dähn and Dr. Marika Vespa for assistance during the measurement campaigns and suggestions during manuscript preparation. The authors wish also to thank Dr. Urs Eggenberger, Verena Jakob, Christine Lemp, and Dr. Christoph Wanner from the University of Bern, for sample preparation, BET measurements and for XRD assistance. This work was partially funded by the Helmholtz Virtual Institute of "Advanced Solid-Aqueous Radiogeochemistry".

\section{References}

1. Witherspoon PA, Bodvarsson GS (2006) Geological challenges in radioactive waste isolation: fourth worldwide review. LBNL59808. Lawrence Berkeley National Laboratory, Berkeley

2. Nagra (2002) Project Opalinus Clay-Safety Report: demonstration of disposal feasibility for spent fuel, vitrified high-level waste and long-lived intermediate-level waste (Entsorgungsnachweis). Nagra Technical Report NTB 02-05, National Cooperative for the Disposal of Radioactive Waste (Nagra), Wettingen

3. SKB (2006) Fuel and canister process report for the safety assessment SR-Can. Technical Report TR-06-22. Svensk 
Kärnbränslehantering $\mathrm{AB}$ Swedish Nuclear Fuel and Waste Management Co, Stockholm (SKB)

4. Weerasooriya R, Tobschall HJ (2005) Pyrite-water interactions: effects of $\mathrm{pH}$ and $\mathrm{pFe}$ on surface charge. Colloids Surf A Physicochem Eng Asp 264(1-3):68-69

5. Bruggeman C, Maes A, Vancluysen J, Vandenmussele P (2005) Selenite reduction in Boom clay: effect of $\mathrm{FeS}_{2}$, clay minerals and dissolved organic matter. Environ Pollut 137(2):209-221

6. Breynaert E, Bruggeman C, Maes A (2008) XANES-EXAFS analysis of Se solid-phase reaction products formed upon contacting $\mathrm{Se}(\mathrm{IV})$ with $\mathrm{FeS}_{2}$ and FeS. Environ Sci Technol 42(10): 3595-3601

7. Scheinost AC, Charlet L (2008) Selenite reduction by mackinawite, magnetite and siderite: XAS characterization of nanosized redox products. Environ Sci Technol 42(6):1984-1989

8. Scheinost AC, Kirsch R, Banerjee D, Fernandez-Martinez A, Zaenker H, Funke H, Charlet L (2008) X-ray absorption and photoelectron spectroscopy investigation of selenite reduction by FeII-bearing minerals. J Contam Hydrol 102:228-245

9. Luther GW III (1991) Pyrite synthesis via polysulfide compounds. Geochim Cosmochim Acta 55(10):2839-2849

10. Moses CO, Herman JS (1991) Pyrite oxidation at circumneutral pH. Geochim Cosmochim Acta 55(2):471-482

11. van Hullenbusch E, Farges F, Lenz M, Lens P, Brown GE Jr (2006) Selenium speciation in biofilms from granular sludge bed reactors used for wastewater treatment. XAFS 13 conference, July 9-14, 2006, Stanford

12. Koningsberger DC, Prins R (1987) X-ray absorption-principles, applications, techniques of EXAFS, SEXAFS and XANES. Chemical analysis, vol 92. Wiley, New York

13. Carlson TA, Nestor CW Jr, Tucker TC, Malik FB (1968) Calculation of shake-off for elements from $\mathrm{z}=2$ to 92 with the use of self-consistent-field wave functions. Phys Rev 169:27-36

14. Charlet L, Mingliang K, Bardelli F, Kirsch R, Géhin A, Grenèche J-M J, Chen F (2012) Nanocomposite pyrite-greigite reactivity toward Se(IV)/Se(VI). Environ Sci Technol 46:4869-4876

15. Hummel W, Berner U, Curti E, Pearson FJ, Thoenen T (2002) Nagra/PSI chemical thermodynamic data base 01/01. Universal Publishers, Parkland
16. Olin A, Nolang B, Ohman LO, Osadchii E, Rosen E (2005) In: Mompean FJ, Perrone J, Illemassène $M$ (eds) Chemical thermodynamics of selenium. Chemical thermodynamics 7. OECD Nuclear Energy Agency, Elsevier, Amsterdam

17. Williamson MA, Rimstidt JD (1994) The kinetics and electrochemical rate-determining step of aqueous pyrite oxidation. Geochim Cosmochim Acta 58(24):5443-5454

18. Aimoz L, Curti E, Mäder U (2011) Iodide interaction with natural pyrite. J Radioanal Nucl Chem 288:517-524

19. Kosmulski M (2009) pH-dependent surface charging and points of zero charge IV Update and new approach. J Coll Interf Sci 337(2):439-448

20. Yllera de Llano A, Bidoglio G, Avogadro A, Gibson PN, Rivas Romero P (1996) Redox reactions and transport of selenium through fractured granite. J Contam Hydrol 21:129-139

21. Myneni SCB, Tokunaga TK, Brown GE (1997) Abiotic selenium redox transformations in the presence of Fe(ii, iii) oxides. Science 278:1106-1109

22. Stanton RL (1972) Ore petrology. McGraw-Hill, New York

23. Sakai Y, Tomura K, Ohshita K (1994) Determination of selenium(IV) and selenium(VI) in natural water samples by neutron activation analysis after chemical pre-collection. J Radioanal Nucl Chem 187(6):441-450

24. Finkelman RB, Mrose ME (1977) Downeyite, the first verified natural occurrence of $\mathrm{SeO}_{2}$. Am Mineral 62:316-320

25. Lide DR (ed) CRC handbook of chemistry and physics, 90th edn (2009-2010). Maryland (USA) edn. CRC Press, Taylor and Francis Group, Boca Raton

26. Curti E, Crovisier JL, Karpoff AM, Morvan G (2006) Long-term corrosion of two nuclear waste reference glasses (MW and SON68): a kinetic and mineral alteration study. Appl Geochem 21:1152-1168

27. Lee CP, Jan YL, Lan PL, Wei YY, Teng SP, Hsu CN (2007) Anaerobic and aerobic sorption of cesium and selenium on mudrock. J Radioanal Nucl Chem 274(1):145-151 